\title{
PAPEL DA ANGIOTENSINA-(1-7) E DAS VIAS DE SINALIZAÇÃO PI3K/Akt/FOXO E PI3K/Akt/mTOR NA HIPERTROFIA CARDIOMIOCÍTICA INDUZIDA POR HORMÔNIO TIREOIDIANO
}

Tese apresentada ao Programa de Pós-Graduação em Biologia de Sistemas do Instituto de Ciências Biomédicas da Universidade de São Paulo, para obtenção do Título de Doutor em Ciências.

Área de concentração: Biologia Morfofuncional

Orientadora: Prof ${ }^{\mathrm{a}}$. Dr ${ }^{\mathrm{a}}$. Maria Luiza Morais Barreto de Chaves

Coorientador: Prof. Dr. Robson Augusto dos Santos

Versão original

\section{São Paulo}




\section{RESUMO}

\section{SENGER, N. Papel da Angiotensina-(1-7) e das vias de sinalização PI3K/Akt/FOXO e PI3K/Akt/mTOR na hipertrofia cardiomiocítica induzida por}

hormônio tireoidiano. 2019. 112 f. Tese (Doutorado em Biologia de Sistemas) - Instituto de Ciências Biomédicas, Universidade de São Paulo, São Paulo, 2019.

Elevados níveis de hormônios tireoidianos (HT), como aqueles encontrados no hipertireoidismo, induzem a hipertrofia das células musculares cardíacas, a qual se confirma experimentalmente in vivo e in vitro. Resultados prévios do nosso grupo de pesquisa demonstraram que elevados níveis plasmáticos do peptídeo Angiotensina-(1-7) (Ang-(1-7)) inibem a hipertrofia cardíaca induzida pelos HT em ratos. Entretanto, os mecanismos moleculares envolvidos nessas ações da Ang-(1-7) ainda não foram totalmente elucidados e mais estudos são necessários. Neste contexto, o presente estudo teve como objetivo avaliar o possível envolvimento das vias de sinalização PI3K/Akt/mTOR e PI3K/Akt/FOXO para a deflagração desse efeito anti-hipertrófico promovido pela Ang-(1-7). Para isso, culturas primárias de cardiomiócitos obtidas a partir de ratos neonatos foram preparadas e tratadas com triiodotironina (T3) e/ou Ang-(1-7). Os resultados obtidos por diferentes técnicas experimentais mostraram significativa ação anti-hipertrófica da Ang-(1-7) frente às ações tróficas do T3 in vitro, ocorrendo mediante a ativação do receptor MAS. Em relação aos mecanismos moleculares, o tratamento com T3 ou Ang-(1-7) levou ao aumento da Akt fosforilada, indicando a ativação dessa quinase, assim como da proteína downstream mTOR. Por outro lado, embora o T3 não influencie na atividade de FOXO3, o tratamento com Ang(1-7) resultou na ativação desta proteína, evidenciada por uma redução na sua forma inativa (p-FOXO3), bem como por seu maior acúmulo nuclear. A ativação de FOXO3 mostrou-se ser fundamental para os efeitos anti-hipertróficos da Ang-(1-7). Como consequência ao aumento de FOXO3, foi observada maior expressão das enzimas antioxidantes (superóxido dismutase e catalase) e menor concentração de espécies reativas de oxigênio (EROs) nas células tratadas com Ang-(1-7). Além disso, uma outra contribuição interessante deste estudo foi a observação de uma regulação negativa nos níveis do receptor AT1 e do peptídeo Angiotensina II (Ang II) frente ao tratamento com Ang-(1-7) nos cardiomiócitos. Em conjunto, esses resultados sugerem um novo mecanismo anti-hipertrófico da Ang-(1-7) frente às ações do T3, o que pode vir a contribuir para o estudo de futuros alvos terapêuticos.

Palavras-chaves: Hipertrofia cardíaca. Hormônio tireoidiano. Sistema Renina-Angiotensina. Angiotensina-(1-7). mTOR. FOXO. SOD1. Catalase. Espécies reativas de oxigênio. 


\begin{abstract}
SENGER, N. Role of Angiotensin-(1-7) and PI3K/Akt/FOXO and PI3K/Akt/mTOR signaling pathway in thyroid hormone-induced cardiomyocytic hypertrophy. 2019. 112 p. PhD Thesis (Lyfe Systems Biology) - Instituto de Ciências Biomédicas, Universidade de São Paulo, São Paulo, 2019.
\end{abstract}

High levels of thyroid hormone (TH), such as found in hyperthyroidism, induce a hypertrophic phenotype in cardiac muscle cells, which is experimentally confirmed in vivo and in vitro conditions. Previous results from our group demonstrated that the upregulation of Angiotensin-(1-7) peptide (Ang-(1-7)) is able to prevent the TH-induced cardiac hypertrophy. However, the molecular mechanisms involved in these Ang-(1-7) effects have not been fully elucidated and further studies are needed. In this context, the present study aimed to evaluate the possible involvement of the PI3K/Akt/mTOR and PI3K/Akt/FOXO signaling pathways in the Ang-(1-7) antihypertrophic effect. Primary cultures of cardiomyocytes obtained from neonatal Wistar rats were prepared and treated with triiodothyronine (T3) and/or Ang-(1-7). The results showed a significative antihypertrophic effect of Ang-(1-7) against the trophic actions of $\mathrm{T} 3$ in vitro, which has been confirmed by different experimental approaches and occurs through the activation of MAS receptor. Regarding molecular mechanisms, treatment with T3 or Ang-(1-7) led to increased phosphorylated Akt (serine 473 and threonine 308) in cardiomyocytes, indicating the activation of this kinase, as well as the downstream protein mTOR. On the other hand, although T3 does not influence the FOXO3 activity, treatment with Ang-(1-7) resulted in its activation, evidenced by reduction in its inactive form ( $\mathrm{p}$ FOXO3), as well as by greater nuclear accumulation of this protein, which proved to be essential for the Ang-(1-7) antihypertrophic effect. In addition, as consequence of increased FOXO3, high expression of antioxidant enzymes (superoxide dismutase and catalase) and low reactive oxygen species (ROS) concentration were observed in cells treated with Ang-(1-7). Interestingly, a negative regulation of AT1 receptor and Angiotensin II (Ang II) levels were detected in cells treated with Ang-(1-7). Together, these results suggest a new antihypertrophic mechanism of Ang-(1-7) in T3-induced cardiomyocyte hypertrophy, which may contribute to the study of future therapeutic targets.

Keywords: Cardiac hypertrophy. thyroid hormone. Renin Angiotensin System. Angiotensin(1-7). mTOR. FOXO. SOD1. Catalase. Reactive oxygen species. 


\section{INTRODUÇÃO}

\subsection{Hipertrofia cardíaca}

As doenças cardiovasculares continuam sendo a principal causa de morbidade e mortalidade no mundo ocidental, sendo a insuficiência cardíaca a doença cardiovascular com maior crescimento nas últimas décadas. Embora diferentes estímulos possam induzir a insuficiência cardíaca, uma resposta inicial comum a esses estímulos é um processo de crescimento do coração, chamado de "hipertrofia cardíaca" (KANNEL, 2000; HOBBS, 2004). Neste contexto, de maneira geral, a instalação de um processo hipertrófico no coração consiste em um mecanismo compensatório ou adaptativo do coração, a fim de diminuir o estresse da parede ventricular e manter, ou até mesmo aumentar, a função do coração (revisado em MAILLET; van BERLO; MOLKENTIN, 2013). No entanto, a longo prazo, a hipertrofia cardíaca predispõe o coração a eventos arrítmicos, morte celular e aumento do número de células não musculares (proliferação de fibroblastos), o que resulta em fibrose do órgão e progressão para o quadro de insuficiência cardíaca (BERENJI et al., 2005).

Os estímulos iniciais para instalação de um processo hipertrófico podem ser amplamente agrupados em estímulos biomecânicos e sensíveis ao estiramento, ou estímulos neurohumorais, que estão associados à liberação de citocinas, fatores de crescimento peptídicos ou hormônios, a exemplo dos hormônios tireoidianos (revisado em HEINEKE; MOLKENTIN, 2006).

Em nível celular, $85 \%$ do volume do coração é composto pelos cardiomiócitos, que representam as células musculares e contêm uma série de unidades contráteis básicas chamadas de sarcômeros (HEINEKE; MOLKENTIN, 2006). Ao contrário das demais células que compõem o coração (tais como células endoteliais, fibroblastos, células musculares lisas, entre outras), os cardiomiócitos apresentam pequena capacidade de proliferar após o nascimento (BERGMANN et al., 2009; KAJSTURA et al., 2012). Nesse sentido, o processo de hipertrofia cardíaca ocorre principalmente através do aumento do tamanho dos cardiomiócitos individuais e, portanto, não é acompanhado por multiplicação dessas células (BERNARDO et al., 2010). Tal crescimento deve-se à adição de sarcômeros em paralelo ou em série nos cardiomiócitos, instalando uma hipertrofia concêntrica ou excêntrica respectivamente, o que requer, a princípio, um aumento na síntese proteica (esquematizado na Figura 1) (GROSSMAN; JONES; McLAURIN, 1975). 


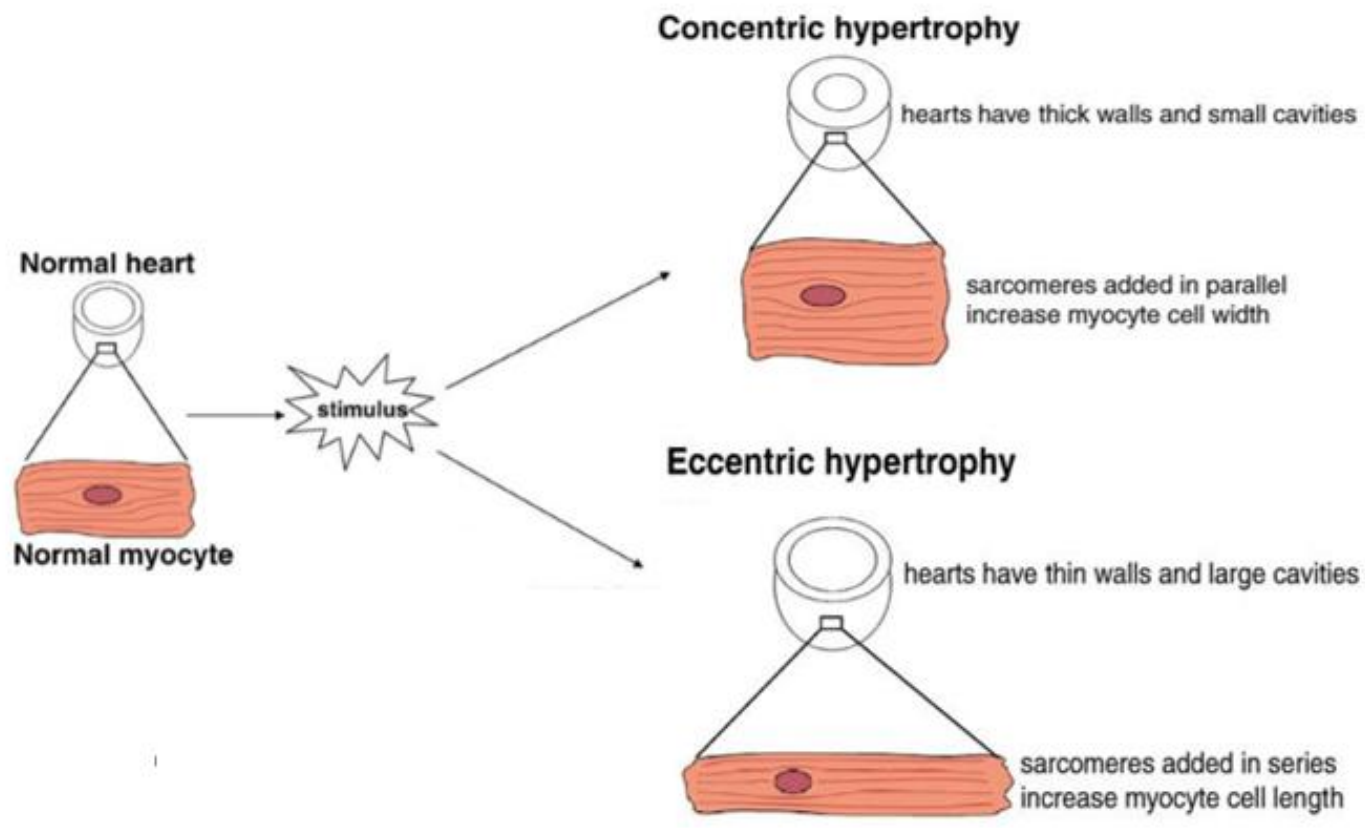

Figura 1. Diferentes fenótipos de hipertrofia cardíaca. A adição de sarcômeros em paralelo resulta em hipertrofia concêntrica, a qual é caracterizada pelo espessamento da parede ventricular em detrimento da cavidade ventricular. Por outro lado, a adição de sarcômeros em série resulta na hipertrofia excêntrica, caracterizada pela presença de parede ventricular fina com aumento da cavidade ventricular (Adaptado de BERNARDO et al., 2010).

Em relação aos mecanismos moleculares envolvidos na hipertrofia cardíaca, diferentes vias de sinalização intracelular relacionadas com o aumento da síntese proteica já foram descritas por participarem desse processo (revisado em HAQ et al., 2001). Além disso, durante a hipertrofia do cardiomiócito também são observadas alterações na transcrição de inúmeros genes e ativação de genes fetais que voltam a ser expressos na fase adulta, tais como peptídeo natriurético cerebral (BNP), peptídeo atrial natriurético (ANP) e miosina de cadeia pesada do tipo $\beta$ ( $\beta$-MHC), os quais podem ser considerados marcadores hipertróficos (OGAW; BOLD, 2014).

Entretanto, embora diversos trabalhos venham contribuindo para o melhor entendimento deste processo, muitos eventos ainda não foram totalmente elucidados, visto a complexidade de inúmeras vias de sinalização envolvidas, as quais, muitas vezes, convergem em respostas comuns. Nesse sentido, a elucidação de novos mecanismos, assim como a interação com outros sistemas e moléculas, é fundamental para a compreensão do processo hipertrófico por inteiro, além de contribuir para o desenvolvimento de novas estratégias terapêuticas. 


\subsection{Hormônio tireoidiano e o coração}

A glândula tireoide é responsável pela síntese de dois importantes hormônios: Tiroxina (T4) e Triiodotironina (T3). Embora o T3 seja considerado o hormônio biologicamente ativo, a maior síntese hormonal desta glândula corresponde ao T4. Contudo, na circulação ou em tecidos específicos, como no caso do coração, o T4 é rapidamente convertido em T3 por ação das enzimas iodotironinas desiodases tipo I e II (D1 e D2), responsáveis por promover uma reação de monodesiodação (BIANCO; BRIAN, 2006).

Dentre as diversas ações fisiológicas atribuídas ao T3 no organismo em geral, o coração corresponde a um dos principais órgãos-alvo deste hormônio (KLEIN; OJAMAA, 2001). Quando em altas concentrações, os hormônios tireoidianos (HT) promovem aumento da força e da velocidade de contração sistólica, além de uma queda na resistência periférica vascular (KLEIN; OJAMAA, 2001). O aumento do volume sistólico e da frequência cardíaca é determinante para a ação dos HT aumentando o débito cardíaco, contribuindo para o aumento da pressão arterial sistólica (DANZI; KLEIN, 2012). Sendo assim, disfunções na glândula tireoide estão muito associadas com doenças cardiovasculares, uma vez que o hiperdinamismo cardíaco, frequentemente observado em pacientes hipertireoideos, no longo prazo, resulta em taquicardia, arritmia cardíaca e fibrilação atrial (DANZI; KLEIN, 2012).

Quando em altas concentrações, os HT também são responsáveis por desencadear um processo hipertrófico no coração mediante uma ação direta desses hormônios nos cardiomiócitos (KAHALY, DILMANN, 2005). A hipertrofia cardíaca induzida por elevados níveis de HT é caracterizada inicialmente como uma hipertrofia concêntrica e compensada, uma vez que inicialmente não acarreta em prejuízos à função do coração. No entanto, a longo prazo, os elevados níveis séricos de T3 podem acarretar em uma hipertrofia com prejuízos funcionais, também chamada de hipertrofia descompensada, com alterações na excitabilidade cardíaca e danos mitocondriais, podendo progredir para insuficiência cardíaca (SIU et al., 2007; MAYTY et al., 2013).

Em relação aos mecanismos moleculares, as ações dos HT modulando o trofismo cardíaco ocorrem por ações genômicas, decorrentes de sua ligação a receptores nucleares específicos, denominados receptores TRs, a qual leva à regulação da expressão de seus genes alvos. Para que essas ações genômicas ocorram são necessárias algumas horas (KLEIN; OJAMAA, 2001). No entanto, outra visão a respeito das ações dos HT foi proposta há alguns anos, denominada de ação não genômica. Estas ações ocorrem de maneira independente da ligação dos HT aos receptores TRs nucleares, permitindo ações extranucleares muito rápidas, 
na ordem de segundos ou minutos. Tais ações estão intimamente relacionadas com alterações pós-transcricionais de proteínas, a exemplo da regulação do estado de fosforilação de algumas proteínas envolvidas em diferentes vias de sinalização (YEN, 2001; DAVIS; LEONARD; DAVIS, 2008). Neste contexto, já foi demonstrado que o T3 é capaz de ativar diversas vias de sinalização que participam do processo hipertrófico no coração, a exemplo das vias PI3K/Akt/mTOR (fosfoinositídeo 3-quinase/ proteína quinase B/ mammalian target of rapamycin), AMPK (proteína quinase ativada por AMP), ERK (quinase extracelular regulada por sinal), MyD88/NF-kB (fator de diferenciação mieloide 88/ fator nuclear kappa B), NFAT (fator nuclear das células $\mathrm{T}$ ativadas) entre outras (KENESSEY; OJAMAA, 2006; IORDANIDOU; HADZOPOULOU-CLADARAS; LAZOU， 2010; TAKANO; DINIZ; BARRETO-CHAVES, 2013; TAKANO et al., 2017).

Além disso, vários relatos da literatura também revelaram aumento de enzimas oxidativas e de espécies reativas de oxigênio (EROs), bem como uma diminuição das enzimas antioxidantes em corações hipertireoideos, indicando um estado de estresse oxidativo aumentado nesse órgão (ASAYAMA et al., 1987; ASAYAMA et al., 1989a, 1989b; GREDILLA; BARJA; LOPEZ-TORRES, 2001; MORENO et al., 2005; ARAUJO et al., 2008). Estendendo esses dados, foi demonstrado que o tratamento combinado com antioxidantes é capaz de prevenir a hipertrofia cardíaca induzida por HT in vivo e in vitro, evidenciando um importante papel também das EROs para o processo hipertrófico no coração (ARAUJO et al., 2011; MISHRA et al., 2019).

\subsection{Sistema Renina-Angiotensina}

O Sistema Renina-Angiotensina (SRA) é um sistema endócrino fundamental para a manutenção da homeostasia do sistema cardiovascular. Neste sentido, um desbalanço em seus componentes pode acarretar em hipertensão arterial, aterosclerose, hipertrofia cardíaca e insuficiência cardíaca (NAVAR, 2014).

O SRA clássico é composto inicialmente pela Renina, produzida pelas células justaglomerulares do rim, cuja função é clivar o Angiotensinogênio (Ang) em Angiotensina I (Ang I), um decapeptídeo biologicamente inativo. Por ação da Enzima Conversora de Ang I (ECA), localizada em células vasculares endoteliais, a Ang I é convertida em Angiotensina II (Ang II), um octapeptídeo biologicamente ativo e considerado por muito tempo como o principal peptídeo efetor desse sistema (CORVOL et al., 1995). A Ang II se liga a dois receptores 
específicos acoplados à proteína G, AT1 e AT2 (Figura 2). Quando o receptor AT1 é ativado pela Ang II promove efeitos vasoconstritores, contribui para o desenvolvimento de aterosclerose e respostas inflamatórias, além de ativar diversas vias hipertróficas nos cardiomiócitos, tais como MAPK (proteína quinase ativada por mitógeno) e ERK1/2, as quais estão relacionadas com a instalação de uma hipertrofia descompensada com fibrose e morte celular (GRIENDLING et al., 1997; BALAKUMAR; JAGADEESH, 2014). O receptor AT2, por sua vez, apresenta importante participação no desenvolvimento embriológico e, quando ativado pela Ang II, promove efeitos na maioria das vezes contrários aos deflagrados pela ativação do receptor AT1, como efeitos vasodilatadores e anti-hipertróficos (NOUET; NAHMIAS, 2000; DANYEL et al., 2013).

Apesar do SRA ter sido considerado, por muito tempo, apenas um sistema endócrino dependente da atividade da renina sintetizada pelos rins, hoje já se sabe que existe o SRA local, uma vez que diversos tecidos são capazes de sintetizar, no seu interior, alguns dos componentes deste sistema de forma independente do SRA circulante (DZAU et al, 1986; DZAU; RE, 1987). No coração, já foi verificada a expressão gênica de Ang, ECA e dos receptores AT1 e AT2, possibilitando a síntese local de Ang II, bem como a sua ação, mediante ligação aos receptores (RE, 2004). É importante ressaltar que aproximadamente 90\% da Ang I e 75\% da Ang II presentes no coração são provenientes da síntese local, demonstrando a importância do SRA local (VAN KATS et al., 1998). Posteriormente, também foi descrito o SRA subcelular ou intrácrino, como é o caso do SRA presente na mitocôndria, no retículo endoplasmático e no núcleo, os quais agem de maneira independente do SRA local e do circulante (TADEVOSYAN et al., 2010; ABADIR et al., 2011; ABADIR; WALSTON; CAREY, 2012).

\subsection{Angiotensina-(1-7)}

Além dos peptídeos constituintes do SRA clássico, apresentados no item 1.3, outros peptídeos foram identificados posteriormente, como o heptapeptídeo Angiotensina-(1-7) (Ang-(1-7)), o que permitiu uma visão muito mais ampla sobre as ações fisiopatológicas atribuídas a este sistema (revisado em BALAKUMAR; JAGADEESH, 2014; SANTOS et al., 2019).

A principal síntese da Ang-(1-7), no coração, ocorre a partir da Ang II, por ação da Enzima Conversora de Angiotensina II (ECA2) (SANTOS et al., 1988). Por outro lado, a 
ECA2 também pode clivar a Ang I em Angiotensina-(1-9) (Ang-(1-9)) (DONOGHUE et al., 2000), a qual irá ser convertida em Ang-(1-7) pela ação enzimática da ECA ou da endopeptidase neutra (NEP) (RICE et al., 2004). Além disso, a Ang-(1-7) também pode ser sintetizada diretamente da Ang I por ação da NEP e da propil-endopeptidase (PEP) (KEIDAR; KAPLAN; GAMLIEL-LAZAROVICH, 2007) (Esquematizado na Figura 2).

A Ang-(1-7) se liga a um receptor específico acoplado à proteína G (GPCR), denominado receptor MAS (SANTOS et al., 2003b), o qual foi originalmente descrito em 1986 por Young e colaboradores como um proto-oncogene humano. Quando este receptor é ativado pela Ang(1-7) promove diversas ações cardioprotetoras, tais como efeitos vasodilatadores, uma vez que aumenta a síntese de óxido nítrico (NO) por ativação da via PI3K/Akt/NO e potencializa os efeitos da bradicinina, diminui a resposta inflamatória e promove efeitos antiarritmogênicos (SAMPAIO et al., 2007; DIAS-PEIXOTO et al., 2008). No cardiomiócito, a Ang-(1-7) promove respostas anti-hipertróficas, visto que impede ativação das MAPKs (TALLANT; FERRARIO; GALLACHER, 2005) e ativa a via anti-hipertrófica NO/GMPc (ENÉAS et al., 2009), além de agir sobre proteínas associadas com o remodelamento cardíaco, diminuindo a deposição de colágeno (GROBE et al., 2006). Sendo assim, a Ang-(17) apresenta ações cardioprotetoras, opostas às ações da Ang II via receptor AT1 e, portanto, corresponde a um importante braço contra-regulatório dentro do SRA (BALAKUMAR; JAGADEESH, 2014).

Em relação ao metabolismo da Ang-(1-7), esse peptídeo pode ser clivado pela aminopeptidase A (AP), formando a Angiotensina-(2-7), ou pela ECA formando a Angiotensina-(1-5) (revisado em SANTOS et al., 2018). Além disso, mais recentemente foi descrito que a Ang-(1-7) também pode ser convertida em um peptídeo com ação biológica, denominado de Alamandina, ou também chamada de Ala-Ang-(1-7) (LAUTNER et al., 2013) (Figura 2). A Alamandina apresenta um aminoácido Alanina (Ala) que substitui o aminoácido Aspartato (Asp) da Ang-(1-7); nesse sentido a formação de Amalandina pode ocorrer pela descarboxilação de Asp (revisado em SANTOS et al., 2018). Assim como a Ang-(1-7), diversos estudos têm demonstrado um efeito protetor da Alamandina no sistema cardiovascular (revisado em SANTOS et al., 2019). Entretanto, embora a semelhança química entre esses dois peptídeos, a Alamandina se diferencia da Ang-(1-7) por interagir preferencialmente com o receptor denominado $\mathrm{MrgD}$ (Mas-related G-protein coupled receptor member D), o qual também é acoplado à proteína G (LAUTNER et al., 2013; revisado em QARADAKI; APOSTOLOULOS; ZULLI, 2016). 


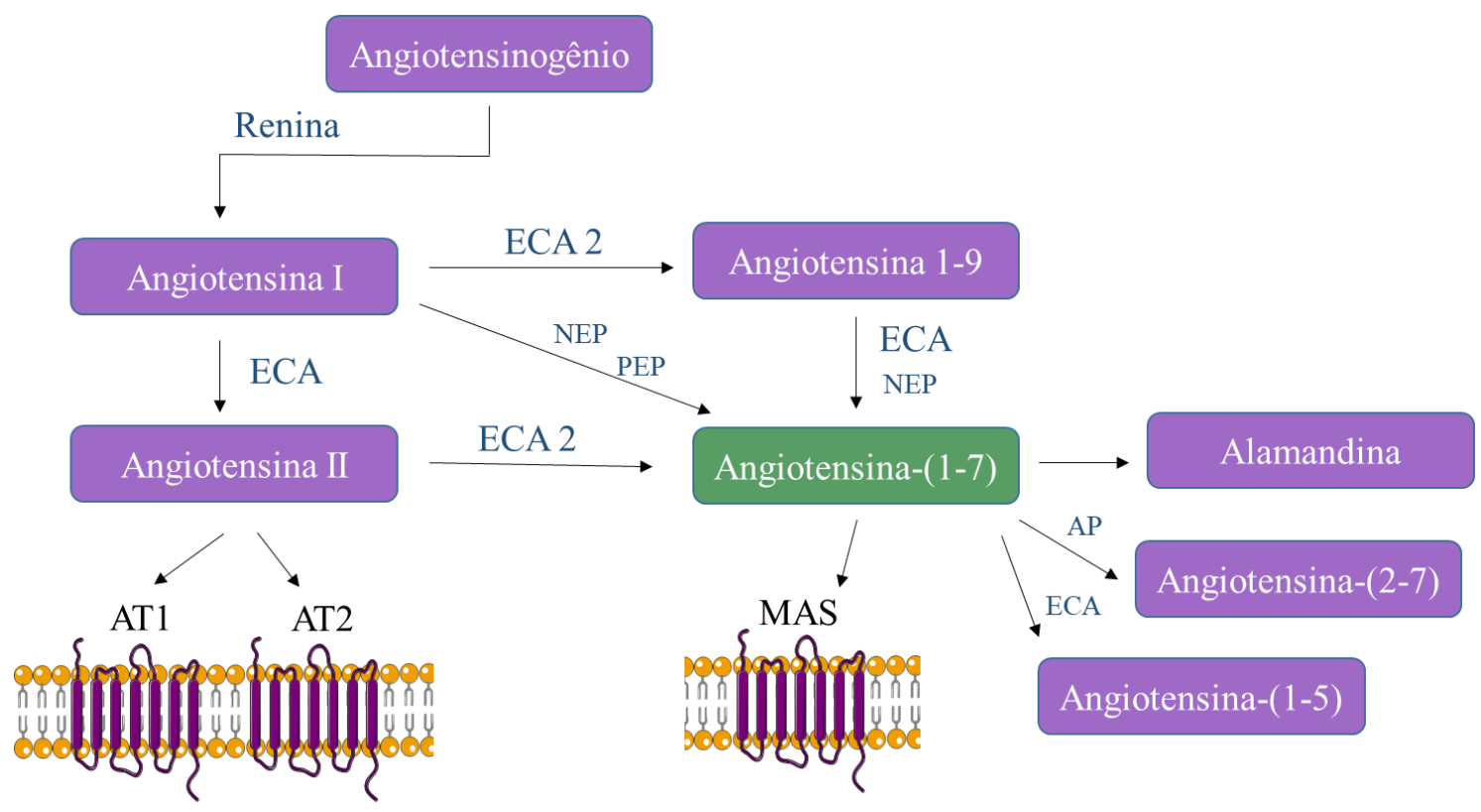

Figura 2. A cascata do Sistema Renina-Angiotensina. ECA, enzima conversora de Angiotensina; ECA2, enzima conversora de Angiotensina II; NEP, endopeptidase neutra; PEP, propil-endopeptidase; AP, aminopeptidase A; AT1, receptor de Angiotensina II tipo I; AT2, receptor de Angiotensina II tipo II (Adaptado de SANTOS et al., 2018).

\section{5 "Cross-talk" entre HT e SRA}

Trabalhos anteriores do nosso grupo, assim como de outros pesquisadores, demonstraram um importante "cross-talk" entre os HT e o SRA, visto que elevados níveis circulantes de T3 promovem aumento dos níveis séricos e cardíacos de renina, Ang II e de seus receptores, AT1 e AT2 (MARCHANT; BROWN; SERNIA, 1993; KOBORI et al., 1997; CARNEIRORAMOS et al., 2006; DINIZ et al., 2012). Além disso, este sistema é um mediador chave para a hipertrofia cardíaca induzida por HT, uma vez que a inibição da síntese ou das ações da Ang II, por inibição da ECA ou dos receptores AT1 e AT2, foi capaz de prevenir total ou parcialmente a hipertrofia cardíaca induzida por T3, comprovando uma importante participação dos componentes do SRA nas ações tróficas dos HT (HU et al., 2003; CARNEIRO-RAMOS et al., 2010).

Em relação ao eixo ECA2/Ang-(1-7)/MAS, dados do nosso grupo demonstraram uma ativação desse eixo em ratos hipertireoideos, com aumento dos níveis cardíacos de Ang-(1-7) e do receptor MAS, além de um aumento na atividade enzimática da ECA2 cardíaca (DINIZ et al., 2016). Sendo assim, os componentes contra-regulatórios do SRA também estão 
ativados no hipertireoidismo e podem estar contribuindo para modular a hipertrofia cardíaca em resposta aos elevados níveis de T3.

Nesse sentido, um recente trabalho do nosso laboratório demonstrou prevenção da hipertrofia cardíaca e melhora da função cardíaca em ratos transgênicos que superexpressam Ang-(1-7) e foram induzidos ao hipertireoidismo; evidenciando uma importante ação cardioprotetora desse heptapeptídeo frente às ações cardíacas do T3 (SENGER et al., 2018). Com isso, o aumento de Ang-(1-7) sérica poderia corresponder a uma estratégia adicional ao tratamento das cardiopatias comumente observadas em pacientes hipertireoideos, visto que estes pacientes, na maioria das vezes, são tratados com beta-bloqueadores, além de terem os seus níveis de T3 e T4 controlados. Embora tenhamos conhecimento a respeito do importante papel cardioprotetor desencadeado pela Ang-(1-7) no modelo de hipertrofia induzida pelo hipertiroidismo in vivo, os mecanismos moleculares e as vias de sinalização que estariam envolvidas na cardioproteção promovida pela Ang-(1-7) ainda não foram totalmente elucidados, e é neste contexto que o presente estudo vem a contribuir.

\subsection{Via de Sinalização PI3K/Akt/mTOR}

Dentre as diversas vias de sinalização que são recrutadas pela ação dos HT nos cardiomiócitos, nosso grupo de pesquisa, assim como outros autores, tem verificado uma importante participação da via PI3K/Akt/mTOR (PANTOS et al., 2008; DINIZ; CARNEIRORAMOS; BARRETO-CHAVES, 2009). Neste sentido, os HT interagem com os receptores TR $\alpha$ presentes no citoplasma de cardiomiócitos, o que promove a ativação de PI3K e consequente fosforilação de Akt nos resíduos treonina (thr) 308 e serina (ser) 473 (OJAMAA; KENESSEY, 2006). A Akt fosforilada, por sua vez, irá fosforilar e ativar mTOR, o qual está envolvido com a regulação de proteínas que controlam a tradução de mRNA, tal como a proteína ribossomal S6K (Figura 3) (GINGRAS; RAUGHT; SONENBER, 2001). Sendo assim, a ativação de mTOR é responsável por aumentar a síntese proteica mediante a estimulação da tradução proteica (DINIZ; CARNEIRO-RAMOS; BARRETO-CHAVES, 2009; YAN et al., 2015). A ativação dessa via de sinalização é indispensável ao processo hipertrófico promovido pelos HT, uma vez que a inibição da mesma, por inibição de PI3K ou de mTOR, inibe este processo (DINIZ; CARNEIRO-RAMOS; BARRETO-CHAVES, 2009).

Dentre os mecanismos regulatórios da ativação de mTOR, a proteína PRAS40 (40kDa proline-rich Akt substrate - também chamada de AKT1S1), quando no estado não fosforilado, 
pode ligar-se a mTOR, impedindo sua fosforilação e atuando, portanto, como um inibidor de mTOR (VANDER HAAR et al., 2007). Embora os estudos ainda sejam incipientes, em células endoteliais foi demonstrado que o tratamento com Ang-(1-7) é capaz de desfosforilar PRAS40 na thr 246 (VERANO-BRAGA et al., 2012). Esse resultado sugere que a Ang-(1-7) induz a ligação de mTOR com PRAS40, levando à inativação de mTOR (VERANO-BRAGA et al., 2012). Embora esse trabalho tenha demonstrado a modulação de mTOR frente ao tratamento com Ang-(1-7) em células endoteliais, não temos conhecimento de outros relatos na literatura mostrando que mTOR possa estar envolvida nas ações da Ang-(1-7) em cardiomiócitos. Assim, este talvez corresponda a um potencial mecanismo que possa explicar os efeitos anti-hipertróficos da Ang-(1-7) e por esse motivo merece ser investigado com maior profundidade, conforme sugerido na Figura 3.

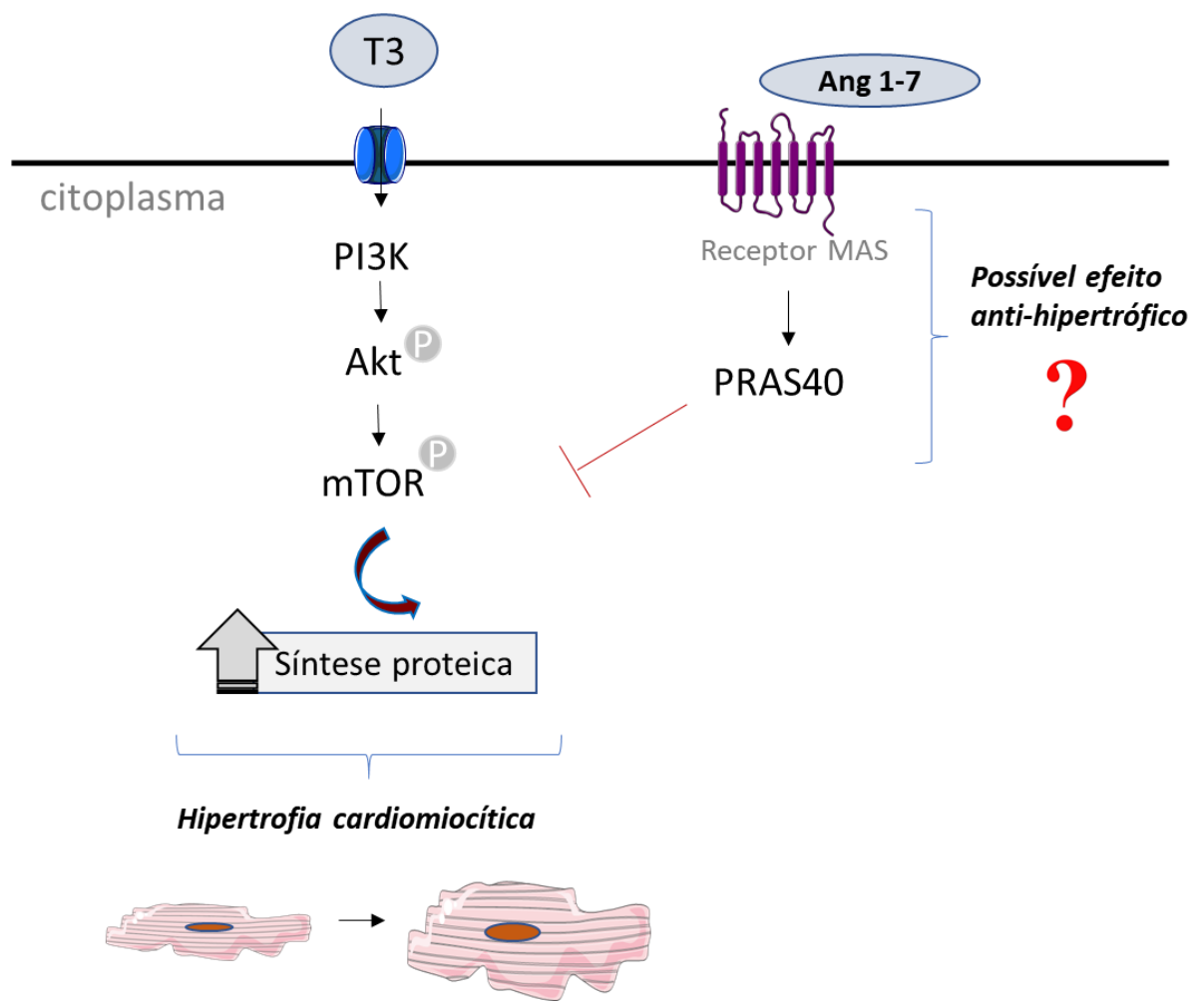

Figura 3. Esquema representativo da via de sinalização PI3K/Akt/mTOR ativada pelos HT nos cardiomiócitos. O T3 interage com o receptor TR $\alpha$ no citoplasma, o que resulta na rápida ativação de PI3K e fosforilação da Akt nos resíduos ser 473 e thr 308. Por sua vez, Akt ativa irá fosforilar mTOR, resultando no aumento da síntese proteica e, consequentemente, na hipertrofia do cardiomiócito. Por outro lado, em células endoteliais, já foi demonstrado que a Ang-(1-7), via receptor MAS, desfosforila PRAS40, a qual interage com mTOR e promove a inativação da mesma; o que poderia corresponder à um mecanismo anti-hipertrófico deste peptídeo (SENGER, 2019). 


\subsection{Via de Sinalização PI3K/Akt/FOXO}

Os fatores de transcrição da família Forkhead box $O$ (FOXO) estão relacionados com a regulação de importantes funções fisiológicas celulares como, por exemplo, de proliferação celular, metabolismo, controle do ciclo celular, degradação de proteínas (proteólise) e apoptose (TRAN et al., 2003; HUANG; TINDALL, 2007). A subfamília FOXO é composta por 4 membros, FOXO1, FOXO3, FOXO4 e FOXO6 (BIGGS; CAVENEE; ARDEN, 2001), sendo que os membros FOXO1 e FOXO3 apresentam papel crítico na manutenção da função cardíaca e no controle do tamanho da célula muscular cardíaca (RONNEBAUM; PATTERSON, 2010). Em camundongos, a deleção gênica de FOXO1 leva à morte fetal, enquanto que a de FOXO3 leva à geração de animais normais ao nascimento, mas com hipertrofia cardíaca e insuficiência cardíaca na fase adulta (HOSAKA et al., 2004; NI et al., 2006).

O principal mecanismo de regulação de FOXO ocorre mediante sua fosforilação pela Akt (KOPS et al., 1999). Quando PI3K fosforila Akt nos resíduos ser 473 e thr 308, a Akt migra para o núcleo, onde é responsável por fosforilar a FOXO1 nos resíduos thr 24 e ser 256 e 319 e a FOXO3 nos resíduos thr 32 e ser 253 e 315. No núcleo, a FOXO fosforilada pela Akt se liga à proteína 14-3-3, é inativada e o complexo FOXO-14-3-3 é translocado para o citoplasma (Figura 4) (BROWNAWELL et al., 2001; BRUNET et al., 2002). Apesar de PI3K-Akt ser o principal mecanismo de regulação da FOXO, SGK1 (Serum/glucocordicoid regulated kinase 1) (BRUNET et al., 2001), CDK2 (quinase dependente de ciclina 2) (HUANG et al., 2006) e $\mathrm{I}_{\mathrm{k}} \mathrm{B}$ também são capazes de fosforilar e inativar FOXO (HU et al., 2004; RONNEBAUM; PATTERSON, 2010).

Em animais transgênicos que superexpressam a forma ativa da Akt, foi verificada a instalação de um processo hipertrófico no coração, acompanhado pela inativação de FOXO (CONDORELLI et al., 2002; MATSUI et al., 2002). O aumento na ativação de Akt e, consequentemente, na inativação de FOXO, contribui para o processo hipertrófico, uma vez que a redução de FOXO resulta na menor expressão de seus genes alvos, tais como Atrogin (Muscle-atrophy F-box, também chamado de MAFbx) e MURF-1 (Muscle RING-Finger protein-1). Estes genes codificam proteínas denominadas de E3-ligases, as quais, no músculo cardíaco, participam do controle do crescimento do coração, visto que promovem a ubiquitinação de proteínas e, consequente, inativação e degradação das mesmas (SKURK et al., 2005; ZENG et al., 2013). 
Neste contexto, dados recentes do nosso grupo de pesquisa evidenciaram que corações de animais submetidos ao hipertiroidismo e que desenvolveram hipertrofia cardíaca apresentam redução na expressão gênica de MURF-1, o que pode sugerir uma inativação de FOXO (LINO; DEMASI; BARRETO-CHAVES, 2019). Entretanto, pouco se sabe sobre o efeito do T3 na atividade de FOXO e, portanto, mais estudos são necessários. Corroborando esses resultados prévios, a inativação de FOXO foi verificada em outros modelos de hipertrofia cardíaca, a exemplo da hipertrofia cardíaca induzida por Ang II ou por sobrecarga de pressão (SKURK et al., 2005; NI et al., 2006).

Por outro lado, ainda no que diz respeito à via de sinalização de FOXO, Verano-Braga e colaboradores (2012) demonstraram que o tratamento com Ang-(1-7), em células endoteliais, diminui a fosforilação de FOXO 1 na ser 256 e aumenta a concentração nuclear dessa proteína, indicando sua ativação frente ao tratamento com Ang-(1-7). Além disso, o tratamento com Ang-(1-7) também promoveu maior acúmulo nuclear de FOXO $1 \mathrm{em}$ linhagem de células tumorais (A549), provavelmente por uma resposta anti-proliferativa da Ang-(1-7) (VERANO-BRAGA et al., 2012). Sendo assim, mais estudos são necessários para verificar uma possível ativação de FOXO pela Ang-(1-7) também em cardiomiócitos, bem como a participação de FOXO nos efeitos anti-hipertróficos desse peptídeo frente às ações do T3. Neste contexto, o presente estudo foi elaborado com o intuito de ampliar o conhecimento a respeito dos mecanismos moleculares deste peptídeo, o que pode vir a contribuir para o estudo de futuros alvos terapêuticos.

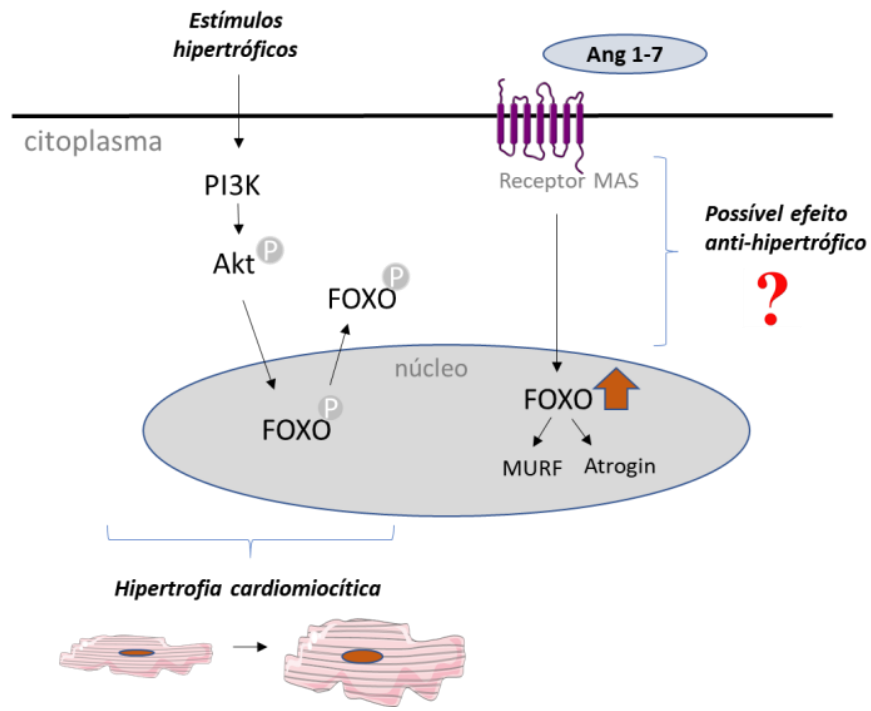

Figura 4. Esquema da via de sinalização PI3K/Akt/FOXO. Diferentes estímulos hipertróficos ativam PI3K e Akt, a qual inativa FOXO e promove a sua expulsão nuclear. Entretanto, em células endoteliais, a Ang-(1-7), via receptor MAS, aumenta FOXO1 no núcleo, o que permite maior transcrição de seus genes alvos e, possivelmente, um efeito anti-hipertrófico (SENGER, 2019). 


\subsection{CONCLUSÕES}

Com base nos resultados obtidos no presente trabalho, podemos concluir que:

* O tratamento com T3 promove hipertrofia dos cardiomiócitos, a qual é prevenida pelo tratamento concomitante com Ang-(1-7), mediante ativação do receptor MAS.

* O tratamento com T3, bem como com Ang-(1-7), é capaz de ativar completamente a quinase Akt e sua proteína downstream mTOR em cardiomiócitos, o que sugere que esta via de sinalização não está relacionada com os efeitos anti-hipertróficos da Ang-(1-7).

* Em relação à via de sinalização envolvendo FOXO3, embora o tratamento com T3 não apresente efeito sobre atividade dessa proteína, a Ang-(1-7), via receptor MAS, é capaz de ativar FOXO3 e, consequentemente aumentar a expressão de seus alvos downstream (SOD1 e catalase), mostrando-se ser fundamental para o efeito anti-hipertrófico do peptídeo. Além disso, o tratamento com Ang-(1-7), via FOXO3, reduziu o aumento de EROs promovido pelo tratamento com T3.

Os HT aumentam rapidamente a expressão proteica do receptor AT1 e de Ang I/II, o que é prevenido pelo tratamento concomitante com Ang-(1-7) nos miócitos cardíacos.

* O tratamento com T3 e/ou Ang-(1-7) não alterou a expressão proteica do receptor MrgD.

Dessa forma, em suma, os resultados obtidos no presente estudo elucidaram um mecanismo anti-hipertrófico da Ang-(1-7) bloqueando os efeitos tróficos do T3 em cardiomiócitos in vitro, o que pode vir a contribuir com estudos futuros que visem a prospecção de alvos terapêuticos. 


\section{REFERÊNCIAS}

ABADIR, P. M. et al. Indenfication and characterization of a functional mitochondria angiotensin system. Proceedings of the National Academy of Sciences USA, v.108, n.36, p.14848-14854, 2011.

ABADIR, P. M.; WALSTON, J. D.; CAREY, R. M. Subcellular characteristics of functional intracelular renin-angiotensin system. Peptides, v.32, n.2, p.437-445, 2012.

ALENINA, N. G. et al. Genetically altered animal models for Mas and angiotensin-(1-7). Experimental physiology, v.93, n.5, p.528-537, 2008.

ALESSI, D. R. et al. Characterization of a 3-phosphoinositide-dependent protein kinase which phosphorylates and activates protein kinase Balpha. Curretn Biology, v.7, n.4, p.261269, 1997.

ALESSI, D. R. et al. Mechanism of activation of protein kinase B by insulin and IGF-1. EMBO, v.25, n.23, p.6541-6551, 1996.

ALMEIDA, P. W. et al. Beneficial effects of angiotensin-(1-7) against deoxycortisterone acetate-induced diastolic dysfunction occur independently of changesin blood pressure. Hypertension, v.66, n.2, p.389-395, 2015.

ANDJELKOVIC, M. et al. Role of translocation in the activation and function of protein kinase B. The Journal of Biological Chemistry, v.272, n.50, p.31515-31524, 1997.

AOYAGI, T. Cardiac mTOR protects the heart against ischemia-reperfusion injury. American Journal of Physiology-Heart and Circulatory Physiology, v.303, n.1, p.H75H85, 2012.

ARAUJO, A. S. et al. Myocardial antioxidant enzyme activities and concentration and glutathione metabolism in experimental hyperthyroidism. Molecular and Cellular Endocrinology, v.246, n.1-2, p.133-139, 2006.

ARAUJO, A. S. et al. The role of redox signaling in cardiac hypertrophy induced by experimental hyperthyroidism. Journal of Molecular Endocrnology, v.41, n.6, p.423-430, 2008.

ARAUJO, A. S. R. et al. Oxidative stress activates insulin-like growth factor I receptor protein expression, mediating cardiac hypertrophy induced by thyroxine. Molecular and Celular Biochemistry, v. 303, n.1-2, p.89-95, 2007. 
ARAUJO, A. S. R. et al. Reactive oxygen and nitrogen species balance in the determination of thyroid hormones-induced cardiac hypertrophy mediated by renin-angiotensin system. Molecular and Cellular Endocrinology, v.333, n.1, p.78-84, 2011.

ASAYAMA, K. et al. Lipid peroxidation and free radical scavengers in thyroid dysfunction in the rat: a possible mechanism of injury to heart and skeletal muscle in hyperthyroidism. Endocrinology, v.121, n.6, p.2112-2118, 1987.

ASAYAMA, K. et. al. Effects of beta-adrenergic blockers with different ancillary properties on lipid peroxidation in hyperthyroid rat cardiac muscle. Endocrinology, v.36, n.5, p.687694, 1989a.

ASAYAMA, K. et. al. Vitamin E protects against thyroxine-induced acceleration of lipid peroxidation in cardiac and skeletal muscles in rats. Journal of Nutritional Science and Vitaminology (Tokyo), v.35, n.5, p.407-418, 1989 b.

ASAYAMA, K.; KATO, K. Oxidative muscular injury and its relevance to hyperthyroidism. Free Radical Biology and Medicine, v.8, n.3, p.293-303, 1990.

BALAKUMAR, P.; JAGADEESH, G. A century old renin-angiotensin-system still grows with endless possibilities: AT1 receptor signaling cascades in cardiovascular physiopathology. Cellular Signaling, v.26, n.10, p.2147-2160, 2014.

BARRETO-CHAVES, M. L.; HEIMANN, A.; KRIEGER, J. E. Stimulatory effect of dexamethasone on angiotensin-converting enzyme in neonatal rat cardiac myocytes. Brazilian Journal of Medical and Biological Research, v.33, n.6, p.661-667, 2000.

BEAULOYE, C. et al. AMPK activation, a preventive therapeutic target in the transition from cardiac injury to heart failure. Cardiovascular Research, v.90, n.2, p.224-233, 2011.

BELLACOSA, A. et al. Akt activation by growth factors is a multiple-step process: the role of the PH domain. Oncogene, v.17, n.3, p.313-325, 1998.

BENNION, D. M. et al. Neuroprotective mechanisms oh the ACE2-angiotensin-(1-7)-Mas axis in stroke. Current Hypertension Reports, v.17, n.2, 2015.

BERENJI, K. et al. A. Does load-induced ventricular hypertrophy progress to systolic heart failure? American Journal of Physiology-Heart and Circulatory Physiology, v.289, n. 1, p.H8-H16, 2005.

BERGMANN, O. et al. Evidence for cardiomyocyte renewal in humans. Science, v.324, n. 5923, p.98-102, 2009. 
BERNARDO, B. C. et al. Molecular distinction between physiological and pathological cardiac hypertrophy: experimental findings and therapeutics strategies. Pharmacology \& Therapeutics, v.128, n.1, p.197-227, 2010.

BIANCO, A. C.; BRIAN, W. K. Deiodinases: implications of the local control of thyroid hormone action. The Journal of Clinical Investigation, v.116, n.10, 2006.

BIGGS, W. H.; CAVENEE, W. K.; ARDEN, K. C. Identification and characterization of members of the FKHR (FOX O) subclasse of winged-hellix transcription factors in the mouse. Mamm Genome, v.21, n.6, p.416-425, 2001.

BLACK, F. M. et al. The vascular smooth muscle $\alpha$-actin gene is reactivated during cardiac hypertrophy provoked by load. Journal of Clinical Investigation, v.88, n.5, p.1581-1588, 1991.

BOSNYAK, S. et al. Relative affinity of angiotensin peptides and novel ligands at AT1 and AT2 receptors. Clinical Science, v.121, n.7, p.297-303, 2011.

BRADFORD, M. M. A rapid and sensitive method for the quantitation of microgram quantities of protein utilizing the principle of protein-dye binding. Analytical Biochemistry, v.7, n.72, p.248-254, 1976.

BROSNILHAN, K. B. et al. Enhanced expression of Ang-(1-7) during pregnancy. Brazilian Journal of Medical and Biological Research, v.37, n.8, p.1237-1262, 2004.

BROWNAWELL, A. M. et al. Inhibition of nuclear import by protein kinase B (Akt) regulates the subcellular distribution and activity of the forkhead transcription fator AFX. Mollecular and Cellular Biology, v.21, n.10, p.3534-3546, 2001.

BRUNET, A. et al. 14-3-3 transists to the nucleus and participates in dynamic nucleo cytoplasmatic trasport. The Journal of Cell Biology, v.156, n.5, p.817-828, 2002.

BRUNET, A. et al. Protein kinase SGK mediates survival signals by phosphorylating the forkhead transcription fator FKHRL (FoxO3). Molecular and Cellular Biology, v.21, n.3, p.952-964, 2001.

BRUNET, A. et al. Stress-dependent regulation of FOXO transcription factors by the SIRT1 deacetylase. Science, v.303, n.5666, p.2011-2015, 2004.

CANALS, M. et al. Up-regulation of the angiotensin II type 1 receptor by the Mas protooncogenese is due to constitutive of Gq/G11 by MAS. The Journal of Biological Chemistry, v.281, n.24, p.16757-16767, 2006. 
CAO, D. J. et al. Mechanical unloading activates FOXO3 to trigger Bnip-3-dependent cardiomyocyte atrophy. Journal of the American Heart Association, v.2, n.2, 2013.

CAPPOLA, A. R. et al. Thyroid status, cardiovascular risck and mortality in older adults. JAMA, v.295, n.9, p.1033-1041, 2006.

CARNEIRO-RAMOS, M. S. et al. Blockage of angiotensin II type 2 receptor prevents thyroxine-mediated cardiac hypertrophy by blocking Akt activation. Basic Research in Cardiology, v.105, n.3, p.325-235, 2010.

CARNEIRO-RAMOS, M. S. et al. Tissue-especific modulation of angiotensin-converting enzyme (ACE) in hyperthyroidism. Peptides, v.27, n.11, p.2942-2949, 2006.

CERNIELLO, F. M. et al. MAS1 receptor trafficking involves ERK1/2 activation through a $\beta$-arrestin2-dependent pathway. Hypertension, v.70, n.5, p.982-989, 2017.

CHANG, R. L. et al. Angiotensin-(1-7) attenuated long-term hypoxia-stimulated cardiomyocyte apoptosis by inhibiting HIF-1 $\alpha$ nuclear translocation via Mas receptor regulation. Growth Factors, v.34, n.1-2, p.11-18, 2016.

CIVELEK, S. et al. Oxidative stress in heart tissue of hyperthyroid and iron supplemented rats. Journal of Toxicology and Environmental Health, Part A, v.64, n.6, p.499-506, 2001.

CONDORELLI, G. et al. Akt induces enhanced myocardial contractility and cell size in vivo in transgenic mice. Proceedings of the National Academy Sciences, v.99, n.19, p.1233312338, 2002.

CORVOL, P. et al. Recent advances in knowledge of the structure and function of the Angiotensin I converting enzyme. Journal of Hypertension Supplement, v.13, n.3, p.S3S10, 1995.

COSTA, M. A. et al. Angiotensin-(1-7) upregulates cardiac nitric oxide synthase in spontaneously hypertensive rats. American Journal of Physiolog-Heart and Circulatory Physiology, v.299, n.4, p.H1205-H1211, 2010.

CUI, T. et al. ATRAP, novel receptor associated protein, enhances internalization of AT1 receptor and inhibits vascular smooth muscle cell growth. Biochemical and Biophysical Research Communications, v.279, n.3, p.938-941, 2000.

DANYEL, L. A. et al. Impacto f AT2-receptor stimulation on vascular biology, kidney function, and blood preassure. Integrated Blood Preassure Control, v.6, p.153-161, 2013. 
DANZI, S.; KLEIN, I. Thyroid hormone and the Cardiovascular System. New England Journal of Medicine, v.344, n.7, p.501-509, 2012.

DAVIET, L. et al. Cloning and characterization of ATRAP, a novel protein that interacts with the angiotensin II type 1 receptor. The Journal of Biological Chemistry, v.274, n.24, p.17058-17062, 1999.

DAVIS, P. J.; LEONARD, J. L.; DAVIS, F. B. Mechanism of nongenomic actions of thyroid hormone. Frontiers in Neuroendocrinology, v.29, n.2, p.211-218, 2008.

DE SOUZA, A. M. et al. Angiotensin II and angiotensin-(1-7) inhibit the inner córtex $\mathrm{Na}^{+}$ ATPase activity through AT2 receptor. Regulatory Peptides, v.120, n.1-3, p.167-175, 2004.

DIAS-PEIXOTO, M. F. et al. Molecular mechanisms involved in the angiotensin- $(1-7) / \mathrm{mas}$ signaling pathway in cardiomyocytes. Hypertension, v.52, n.3, p.542-548, 2008.

DIAS-PEIXOTO, M. F. et al. The cardiac expression of Mas receptor is responsive to different physiological and pathological stimulus. Peptides, v.35, n.2, p.196-201, 2012.

DINIZ, G. P. et al. Cardiac ACE2/Angiotensin 1-7/Mas receptor axis is activated in thyroid hormone-induced cardiac hypertrophy. Therapeutic Advances in Cardiovascular Desease, v.10, n.4, p.192-202, 2016.

DINIZ, G. P. et al. New insight into the mechanism associated with the rapid effect of T3 on AT1R expression. Journal of Molecular Endocrinology, v.49, n.1, p.11-20, 2012.

DINIZ, G. P.; CARNEIRO-RAMOS, M. S.; BARRETO-CHAVES, M. L. Angiotensin type 1 receptor mediates thyroid hormone-induced cardiomyocyte hypertrophy through the Akt/GSK-3beta/mTOR signaling pathway. Basic Research in Cardiology, v.104, n.6, p.653667, 2009.

DONOGHUE, M. et al. A novel angiotensin-converting enzyme-related carboxypeptidase (ACE2) converts angiotensin I to angiotensin 1-9. Circulation Research, v.87, n.5, p.E1-9, 2000.

DUSING, R. Mega clinical trials which have shaped the RAS intervention clinical practice. Therapeutic Advances in Cardiovascular Disease, v.10, n.3, p.133-150, 2016.

DZAU, V. J. et al. Identification of renin and angiotensinogen mRNA sequences in mouse and rat brains. Hypertension, v.8, n.6, p.544-548, 1986. 
DZAU, V. J.; RE, R. N. Evidence for the existence of renin in the heart. Circulation, v.75, n.1pt2, p.134-136, 1987.

EBERMANN, L. et al. The Angiotensin-(1-7) receptor agonist AVE0991 is cardioprotective in diabetic rats. European Journal of Pharmacology, v.590, n.1-3, p.276-280, 2008.

EGEA, J. et al. European contribution to the study of ROS: a summary of the findings and prospects for the future from the COST action BM1203 (EU-ROS). Redox Biology, v.13, p.94-162, 2017.

ENÉAS, R. M. et al. Angiotensin-(1-7) prevents cardiomyocyte pathological remodeling through a nitric/guanosine 3',5'cyclic monophosphate-dependen pathway. Hypertension, v.55, p.153-160, 2009.

ETELVINO, G. M.; PELUSO, A. A.; SANTOS, R. A. New components of the ReninAngiotensin System: Alamandine and the Mas-Related G Protein-Couple receptor D. Current Hypertension Reports, v. 433, n.6, p.704-728, 2014.

FENG, J. et al. Identification of a PKB/Akt hydrophobic motif Ser-473 kinase as DNAdependet protein kinase. The Journal of Biological Chemistry, v.279, n.39, p.41189-41196, 2004.

FERNADEZ, V. et al. Superoxide radical generation, NADPH oxidase activity, and cytochrome P-450 content of rat liver microsomal fractions in an experimental hyperthyroid state: Relation to lipid peroxidation. Endocrinology, v.177, n.2, p.496-501, 1985.

FERNANDES, R. O. et al. Redox status and pro-survival/pro-apoptotic protein expression in the early cardiac hypertrophy induced by experimental hyperthyroidism. Cell Biochemistry and Function, v.29, n.7, p.617-623, 2011.

FERREIRA, A. J.; SANTOS, R. A.; ALMEIDA, A. P. Angiotensin-(1-7): cardioprotective effect in myocardial ischemia/reperfusion. Hypertension, v.38, n.3 pt 2, p.665-668, 2001.

FILHO, A. G. et al. Selective increase of angiotensin-(1-7) and its receptor in hearts of spontaneously hypertensive rats subjected to physical training. Experimental Physiology, v.93, n.5, p.589-598, 2008.

FRIDDLE C. J. et al. Expression profiling reveals distinct stes of genes altered during induction and regression of cardiac hypertrophy. PNAS, v.97, n.12, p.6745-6750, 2000.

FUGLESTEG, B. N. et al. Pretreatment with insulin before ischemia reduces infarct size in Langendorff-perfused rat hearts. Acta Physiology, v.195, n.2, p.273-282, 2009. 
FURUYAMA, T. et al. Identification of the different distribution patterns of mRNAs and consensus binding sequences for mouse DAF-16 homologues. Biochemical Journal, v.349, n.pt2, p.629-634, 2000.

GALANDRIN, S. et al. Cardioprotective Angiotensin-(1-7) peptides acts as a natural-biased ligand at the Angiotensin II type 1 receptor. Hypertension, v.68, n.6, p.1365-1374, 2016.

GIANI, J. F. et al. Angiotensin-(1-7) stimulates the phosphorylation of JAK2, IRS-1 and Akt in rat heart in vivo: role of the AT1 and Mas receptors. The American Journal of Physiology -Heart and Circulatory Physiology, v.293, n.2, p.H1154-H1163, 2007.

GIANI, J. F. et al. Chronic infusion of angiotensin-(1-7) improves resistance and hypertension induced by a high-frutose diet in rats. American Journal of Physiology-Endocrinology and Metabolism, v.296, n.2, p.E262-E271, 2008.

GINGRAS, A. C.; RAUGHT, B.; SONENBERG, N. Control of translation by the target of rapamycin proteins. Progress in Molecular and Subcellular Biology, v.27, p.143-174, 2001.

GIRONACCI, M. M. Angiotensin-(1-7): beyond its central effects on blood pressure. Therapeutics Advances in Cardiovascular Disease, v.9, n.4, p.209-216, 2015.

GIRONACCI, M. M. et al. Angiotensin-(1-7) induces MAS receptor internalization. Hypertension, v.58, n.2, p.176-181, 2011.

GOMES, E. R. et al. Angiotensin-(1-7) prevents cardiomyocyte pathological remodeling through a notric oxide/guanosine 3'5'-cyclicmonophosphate-dependent pathway. Hypertension, v.55, n.1, p.153-160, 2010.

GREDILLA, R.; BARJA, G.; LOPEZ-TORRES, M. Thyroid hormone-induced oxidative damage on lipids, glutathione and DNA in the mouse heart. Free Radical Research, v.35, n.4, p.417-425, 2001.

GREER, E. L. et al. The energy sensor AMP-activated protein kinase directly regulates the mammalian FOXO3 transcriptional factor. The Journal of Biological Chemistry, v.282, n.41, p.30107-301119, 2007.

GRIEDLING, K. K. et al. Angiotensin II signaling in vascular smooth muscle. New concepts. Hypertension, v.29, n.1-2, p.366-373, 1997. 
GROBE, J. L. et al. Chronic angiotensin-(1-7) prevents cardiac fibrosis in DOCA-salt modelo hypertension. American Journal of Physiology. Heart and Circulation Physiology, v.290, n.6, p.H2417-H2423, 2006.

GROSSMAN, W., JONES, D., McLAURIN, L. P. Wall stress and patterns of hypertrophy in the human left ventricle. Journal of Clinical Investigation, v.56, n.1, p.56-64, 1975.

GUERREIRO, A. et al. Effect of thyroid status on lipid composition and peroxidation in the mouse liver. Free Radical, v.26, n.1-2, p.73-80, 1999.

GUO, L. et al. Angiotensin-(1-7) attenuates angiotensin II-induced cardiac hypertrophy via a Sirt3-dependent mechanism. American Journal of Physiology-Heart and Circulation Physiology, v.312, n.5, p.H980-H991, 2017.

GWATHMEY, T. Y. M. et al. Angiotensin-(1-7)-ACE2 attenuates reactive oxygen species formation to Angiotensin II within the cell nucleus. Hypertension, v.55, n.1, p.166-171, 2010.

HABIYAKARE, B. et al. Reduction of Angiotensin A and alamandine vasoactivity in the rabbit model of atherogenesis: differential effects of alamandine and Ang-(1-7). International Journal of Experimental Pathology, v.95, n.4, p.290-295, 2014.

HAMMER, A. et al. Role of the receptor MAS in macrophage-mediated inflammation in vivo. Proceedings of the National Academy of Science, v.113, n.49, p.14109-14114, 2016.

HAQ, S. et al. Differential activation of signal transduction pathways in human hearts with hypertrophy versus advances heart failure. Circulation, v.103, n.5, p.670-677, 2001.

HEINEKE, J.; MOLKETIN, J. D. Regulation of cardiac hypertrophy by intracellular signaling pathways. Nature Reviews Molecular Cell Biology, v. 7, n.8, p.589-600, 2006.

HIROTANI, S. et al. Involvement of nuclear factor-kB and apoptosis signal-regulating kinase 1 in G-protein-coupled receptor agonist-induced cardiomyocyte hypertrophy. Circulation, v.105, n.4, p.509-515, 2002.

HOBBS, R. E. Guidelines for the diagnosis and management of heart failure. American Journal of Therapeutics, v.11, p.467-472, 2004.

HOSAKA, T. et al. Disruption of forkhead transcription factor (FOXO) family members in mice reveals their functional diversification. Proccedings of the National Academy of Science USA, v.101, n.9, p.2975-2980, 2004. 
HOUSLEY, M. P. et al. O-GlcNAc regulates FoxO activation in response to glucose. The Journal of Biological Chemistry, v.283, n.24, p.16283-16292, 2008.

HU, L. W. et al. Thyroxine-induced cardiac hypertrophy: influence of adrenergic nervous system versus renin-angiotensin system on myocyte remodeling. American Journal of Physiology. Regulatory, Integrative and Comparative Physiology, v.285, n.6, p.R1473R1480, 2003.

$\mathrm{HU}, \mathrm{M}$. C. et al. IkB kinase promotes tumorigenesis through inhibition of forkhead FoxO3. Cell, v.117, n.1, p.225-237, 2004.

HUANG, H. et al. CDK2-dependent phosphorylation of FoxO1 as an apoptotic response to DNA damage. Science, v. 314, n.5797, p.294-297, 2006.

HUANG, H.; TINDALL, D. J. Dynamic Foxo transcription factors. Journal of Cell Siences, v.120, n.15, p.2479-2487, 2007.

IORDANIDOU, A.; HADZOPOULOU-CLADARAS, M.; LAZOU, A. Non-genomic effects of thyroid hormone in adult cardiac myocytes: relevance to gene expression and cell growth. Molecular and Cellular Biochemistry, v.340, n.1-2, p. 291-300, 2010.

JEZEK, P., HLAVATÁ, L. Mitochondrial in homeostasis of reactive oxygen species in cell, tissues, and organism. The international Journal of Biochemistry \& Cell Biology, v.37, n.12, p.2478-2503, 2005.

KAHALY, G. J.; DILLMANN W. H. Thyroid hormone action in the heart. Endocrine Reviews, v.26, n.5, p.704-728, 2005.

KAJSTURA, J. et al. Cardiomyogenesis in the aging and failing human heart. Circulation, v.126, n.15, p.1869-1881, 2012.

KANNEL, W. B. Vital epidemiology clues in heart failure. Journal of Clinical Epidemiology, v.53, n.3, p.229-235, 2000.

KARNIK, S. S. et al. Significance of angiotensin 1-7 coupling with MAS1 receptor and other GPCRs to the renin-angiotensin system: IUPHAR Review 22. International Union of Basic and Clinical Pharmacology Review, v.174, n.9, p.737-753, 2017. 
KATARE, R. G. et al. Vitamin B1 analog benfotiamine prevents diabetes-induced diastolic dysfunction and heart failure through Akt/Pim-1 mediated survival pathway. Circulation: Heart Failure, v.3, n.2, p.294-305, 2010.

KEIDAR, S.; KAPLAN, M.; GAMLIEL-LAZAROVICH, A. ACE2 of the heart: From angiotensin I to angiotensin (1-7). Cardiovascular Reserach, v.73, n.3, p.463-469, 2007.

KENESSEY, A.; OJAMAA, K. Thyroid hormone stimulates protein synthesis in the cardiomyocyte by activation the Akt-mTOR and p70S6K pathway. Journal of Biology Chemistry, v.281, n.30, p.20666-20672, 2006.

KLEIN, I.; OJAMAA, K. Thyroid hormone and the cardiovascular system. The New England Journal of Medicine, v.344, n.7, p.501-509, 2001.

KOBORI, H. et al. Thyroid hormone stimulates renin synthesis in rat without involving the sympathetic nervous system. American Journal of Physiology, v.272, n.2pt1, p.E227-E232, 1997.

KOPS, G. J. et al. Direct control of the Forkhead transcription factor AFX by protein kinase B. Nature, v.398, n.6728, p.630-634, 1999.

KOSTENIS, E. et al. G-protein-coupled receptor Mas is a physiological antagonist of the angiotensin II type 1 receptor. Circulation, v.111, n.14, p.1806-1813, 2005.

KUO, M. et al. O-glycosylation of FoxO1 increases its transcriptional activity towards the glucose 6-phosphatase gene. FEBS Lett, v.582, n.5, p.829-834, 2008.

KUZMAN, J. A. et al. L-Thyroxine actives Akt signaling in the heart. Journal of Molecular Cellular Cardiology, v.39, n.2, p.251-258, 2005.

KUZMAN, J. A.; O'CONNELL, T. D.; GERDES, A. M. Rapamycin prevents thyroid hormone-induced cardiac hypertrophy. Endocrinilogy, v.148, n.7, p.3477-3484, 2007.

LAUTNER, R. Q. et. al. Discovery and characterization of alamandine: a novel component of the renin-angiotensin system. Circulation Research, v.112, n.8, p.1104-1111, 2013.

LEI, Y. et al. Angiotensin-(1-7) protects cardiomyocytes against high glucose-induced injuries through inhibiting reactive oxygen species-activated leptin-p38 mitogen-activated protein kinase/extracellular signal-regulated protein kinase 1/2 pathways, but not the leptin-cjun N-terminal kinase pathway in vitro. Journal of Diabetes Investigation, v.8, n.4, p.434445, 2017. 
LEONHADT, J. et al. Evidence for heterodimerization and functional interaction of the Angiotensin type 2 receptor and the receptor Mas. Hypertension, v.69, n.6, p.1128-1135, 2017.

LI, H. et al. Atrogin-1/muscle atraophy F-box inhibits calcineurin-dependent cardiac hypertrophy by participating in an SCF ubiquitin ligase complex. The Clinical Investigation, v.114, n.8, p.1058-1071, 2004.

LI, N. et al. Activation of the cardiac proteassome promotes angiotensin II-induced hypertrophy by down-regulation of ATRAP. Journal of Molecular and Cellular Cardiology, v.79, p.303-314, 2015.

LIN, Y. T. et al. Pre-treatment with angiotensin-(1-7) inhibits tumor growth via autophagy by downregulating PI3K/Akt/mTOR signaling in human nasopharyngeal carcinoma xenografs. Journal of Molecular Medicine (Berl), v.96, n.12, p.1407-1418, 2018.

LINO, C. A; DEMASIM.; BARRETO-CHAVES, M. L. M. Ubiquitin proteassome system (UPS) activation in the cardiac hypertrophy of hyperthyroidism. Molecular and Cellular Endocrinology, 2019. In Press.

LOPEZ-ILASACA, M. et al. The Angiotensin II type I receptor-associated protein, ATRAP, is a transmembrane protein and a modulator of angiotensin II signaling. Molecular Biology of the Cell, v.14, n.12, p.5038-5050, 2003.

MA, H. et al. Angiotensin-converting enzyme 2 overexpression protects against doxorubicininduced cardiomyopathy by multiple mechanisms in rats. Oncotarget, v.8, n.15, p.2454824563, 2017.

MACHADO-SILVA, A. et al. Therapeutic uses for Angiotensin-(1-7). Expert opinion on Therapeutic Patents, v.26, n.6, p.669-678, 2016.

MAEJIMA, Y. et al. MuRF-specific RING finger 1 negatively regulates pathological cardiac hypertrophy through downregulation of calcineurin A. Circulation: Heart Failure, v.7, n.3, p.479-490, 2014.

MAILLET, M.; van BERLO, J. H.; MOLKENTIN, J. D. Molecular basis of physiological heart growth: fundamental concepts and new players. Nature, v.14, n.1, p.38-48, 2013.

MANO, T. et al. Effects of thyroid hormone on coenzyme $\mathrm{Q}$ and other free radical scavengers in rat heart muscle. Journal of Endocrinology, v.145, n.1, p.131-136, 1995.

MANUKYAN, M. C. et al. The phosphoinositide-3 kinase survival signaling mechanism in sepsis. Shock, v.34, p.442-449, 2010. 
MARCHANT C.; BROWN, L.; SERNIA, C. Renin-angiotensin system in thyroid dysfunction in rats. Journal of Cardiovascular Pharmacology, v.22, n.3, p.449-445, 1993.

MATSUI, T. et al. Phenotypic spectrum caused by transgenic overexpression of activated Akt in the heart. Journal of Biology Chemistry, v.277, n.25, p.22896-22901, 2002.

MATSUI, T.; ROSENZWEIG, A. Convergent signal transduction pathways controlling cardiomyocytes survival and function: the role of PI 3-kinase and Akt. Journal of Molecular and Cellular Cardiology, v.38, n.1, p.63-71, 2005.

MATSUZAKI, H. et al. Acetylation of FoxO1 alters its DNA-binding ability and sensitivity to phosphorylation. Proceedings of the National Academy Science of the United States, v.102, n.32, p.11278-11283, 2005.

MAYTY, S. et al. Hyperthyroidism causes cardiac dysfunction by mitochondrial impairment and energy depletion. Journal of Endocrinology, v.217, n.2, p.215-228, 2013.

MEIER, R. et al. Mitogenic activation, phosphorilation, and nuclear translocation of protein kinase B $\beta$. The Journal of Biological Chemistry, v.272, n.48, p.30491-30497, 1997.

MENDES, A. C. R. et al. Chronic infusion of angiotensin-(1-7) reduces angiotensin II levels in rats. Regulatory Peptides, v.125, n.1-3, p.29-34, 2005.

MESSARAH, M. et al. Oxidative stress induced by thyroid dysfunction in rat erythrocytes and heart. Environmental Toxicology and Pharmacology, v.31, n.1, p.33-41, 2011.

METHOT, D. et al. Development and application of a biological peptide pump for the study of the in vivo actions of angiotensinpeptides. American Journal of Hypertension, v.14, n.62, p.38S-43S, 2001.

METHOT, D. et al. Tissue targeting of angiotensin peptides. Journal of Biology Chemistry, v.272, n.18, p.12994-12999, 1997.

MIN, L. J. et al. Angiotensin II type 1 receptor-associated protein prevents vascular smooth muscle cell senescence via inactivation of calcineurin/nuclear factor of activated $\mathrm{T}$ cells pathway. Journal of Molecular and Cellular Cardiology, v.47, n.6, p.798-809, 2009. 
MISHRA, P. Possible activation of NRF2 by Vitamin 3/Curcumin against altered thyroid hormone induced oxidative stress via NFkB/Akt/mTOR/KEAP1 signalling in rat heart. Scientific Reports, v.9, n.1, 2019.

MISHRA, P.; SAMANTA, L. Oxidative stress and heart failure in altered thyroid states. Scientific World Journal, v.2012, n.741861, 2012.

MORAES, P. L. et al. Vasodilador effect of Angiotensin-(1-7) on vascular coronary bed of rats: Role of Mas, ACE and ACE2. Protein \& Peptides Letters, v.24, n.9, p.869-875, 2017.

MORENO, J. M. et al. Cardiac and renal antioxidant enzymes and effects of TEMPOL in hyperthyroid rats. American Journal of Physiology-Endocrinology and Metabolism, v.289, n.5, p.E776-783, 2005.

MORI, J. et al. Angiotensin 1-7 mediates renoprotection against diabetic nephrophathy by reducing oxidative stress, inflammation, and lipotoxicity. American Journal of PhysiologyRenal Physiology, v.306, n.8, p.F821,F821, 2014b.

MORI, J. et al. Angiotensin1-7 ameliorates diabetic cardiomyopathy and diastolic dysfunction in $d b / d b$ mice by reducing lipotoxicity and inflammation. Circulation: Heart Failure, v.7, n.2, p.327-339, 2014a.

MURCA, T. M. et al. Oral administration of an angiotensin-converting enzyme 2 activator ameliorates diabetes-induced cardiac dysfunction. Regulatory Peptides, v.177, n.1-3, p.107$115,2012$.

NADU, A. P. et al. Reduced isoproterenol-induced renin-angiotensin changes and extracelular matrix deposition in hearts of TG(A1-7)3292. Journal of American Society of Hypertension, v.2, n.5, p.341-348, 2008.

NASRIN, N. et al. DAF-16 recruits the CREB-binding protein coativador complexto the insulin-like growth fator binding protein 1 promoter in Hep-G2 cells. Proceedings of the National Academy of Science of the United States, v.97, n.19, p.10412-10417, 2000.

NAVAR, L. G. Physiology: hemodynamics, endotelial function, renin-angiotensinaldosterone system, sympathetic nervous system. Journal of the American Society of Hypertension, v.8, n.7, p.519-524, 2014.

NI, Y. G. et al. Foxo transcription factors blunt cardiac hypertrophy by inhibiting calcineurin signaling. Circulation, v.114, n.11, p.1159-1168, 2006. 
NOUET, S.; NAHMIAS, C. Signal transduction from the angiotensin II AT2 receptor. Trends in Endocrinology \& Metabolism, v.11, n.1, p.1-6, 2000.

OGAW, T.; BOLD, A. J. The heart as an endocrine organ. Endocrine conections, v.3, n.2, p.R31-R44, 2014.

OHSHIMA, K. et al. Possible role of angiotensin-converting enzyme 2 and activation of angiotensin II type 2 receptor by angiotensin-(1-7) in improvement of vascular remodeling by angiotensin II type 1 receptor blockade. Hypertension, v.63, n.3, p.53-59, 2014.

OJAMAA, K.; KENESSEY, A. Thyroid hormone stimulates protein synthesis in the cardiomyocyte by activating the Akt-mTOR and p70S6K pathways. The Journal of Biological Chemistry, v.281, n.30, p.20666-20672, 2006.

OPPERMANN, M. et al. Atrap deficiency increases arterial blood pressure and plasma volume. Journal of the American Society of Nephrology, v.21, n.3, p.468-477, 2010.

PANTOS, C. et al. Long-term thyroid hormone administration reshapes left ventricular chamber and improves cardiac function after myocardial infarction in rats. Basic Research Cardiology, v.103, n.3, p.308-318, 2008.

PAPANICOLAU, K. N.; IZUMIYA, Y.; WALSH, K. Forkhead transcription factors and cardiovascular biology. Circular Research, v.102, n.25, p.16-31, 2008.

PAPINSKA, A. M. et al. Angiotensin-(1-7) administration benefits cardiac, renal and progenitor cell function in $\mathrm{db} / \mathrm{db}$ mice. Britsh Journal of Pharmacology, v.172, n.18, p.4443-4453, 2015.

PASSOS-SILVA, D. G.; BRANDAN, E.; SANTOS, R. A. Angiotensin-(1-7) as therapeutic targets beyond heart disease. Trends in Pharmacological Sciences, v.36, n.5, p.310-320, 2015.

PASSOS-SILVA, D. G.; VERANO-BRAGA, T. SANTOS, R. A. Angiotensin-(1-7): beyond the cardio-renal actions. Clinical Science, v.124, n.7, p.443-465, 2013.

PATEL, V. B. et al. ACE2 deficiency worsens epicardial adipose tissue inflammation and cardiac dysfunction in response to diet-induced obesity. Diabetes, v.65, n.1, p.85-95, 2016.

PRISANT, L. M.; GUJRAL, J. S.; MULLOY, A. L. Hyperthyroidism: a sencondy cause of isolated systolic hypertension. Journal of Clinical Hypertension, v.8, n.8, p.596-599, 2006. 
QARADAKI, T; APOSTOLOULOS, V.; ZULLI, A. Angiotensin-(1-7) and Alamandine: Similarities and differences. Pharmacological Research, v.111, p.820-826, 2016.

RAMOS, G. V. et al. Thyroid hormone upregulates MDM2 in rat type I fibre: Implications for skeletal muscle mass regulation. Acta Physiologica, v.222, n.4, 2018.

RE, R. N. Mechanism of disease: local renin-angiotensin-aldosterone systems and the pathogenesis and treatment of cardiocascular disease. Nature Clinical Practice Cardiovascular Medicine, v.1, n.1, p.42-47, 2004.

RICE, G. I. et al. Evaluation of angiotensin-converting enzyme (ECA) its homologue ECA2 and neprilysin in angiotensin peptide metabolism. The Biochemical Journal, v.383, n.8-1, p.45-51, 2004.

RONNEBAUM, S. M.; PATTERSON, C. The FoxO family in cardiac function and dysfunction. Annual Review of Physiology, v.72, p.81-94, 2010.

SABRI, A.; HUGHIE, H. H.; LUCCHESI, P. A. Regulation of hypertrophic and apoptotic signaling pathway by reactive oxygen species in cardiac myocytes. Antioxidants and Redox Signaling, v.5, n.6, p.731-740, 2003.

SAMPAIO, W. O. et al. Angiotensin-(1-7) through receptor Mas mediates endothelial nitric oxide synthase activation via Akt-dependent pathways. Hypertension, v.49, n.1, p.185-192, 2007.

SANTOS, E. et al. Functional rescue of a defective angiotensin II AT1 receptor mutant by the Mas protooncogene. Regulatory Peptides, v.141, n.13, p.159-167, 2007.

SANTOS, R. A. Angiotensin-(1-7). Hypertension, v.63, n.6, p.1138-1147, 2014.

SANTOS, R. A. et al. Characterization of a new selective antagonist for angiotensin-(1-7), DPro7-angiotensin-(1-7). Hypertension, v.41, n.3-2, p.737-743, 2003a.

SANTOS, R. A. et al. Converting enzyme activity and angiotensin metabolism in the dog brainstem. Hypertension, v.11, n.2-2, p.153-157, 1988.

SANTOS, R. A. et al. Expression of an angiotensin-(1-7)-producing fusion protein produces cardioprotective effects in rats. Physiology Genomics, v.17, n.3, p.292-299, 2004. 
SANTOS, R. A. S. et al. Angiotensin-(1-7) is an endogenous ligand for the G protein-couple receptor Mas. Proceedings of the National Academy of Sciences, v.100, n.14, p.8258-8263, 2003b.

SANTOS, R. A. S. et al. Characterization of a new angiotensin antagonist selective for angiotensin-(1-7): evidence that the actions of Angiotensin-(1-7) are mediated by specific angiotensin receptors. Brain Research Bulletin, v.35, v.4, p.293-298, 1994.

SANTOS, R. A. S. et al. Impairment of in vitro and in vivo heart function in angiotensin-(1-7) receptor Mas knockout mice. Hypertension, v.47, n.5, p.996-1002, 2006.

SANTOS, R. A. S. et al. The Ace2/Angiotensin-(1-7)/Mas axis of the Renin-Angiotensin system: Focus on Angiotensin-(1-7). Physiological Reviews, v.98, n.1, p.505-553, 2018.

SANTOS, R. A. S. et al. The renin-angiotensin system: going beyoud the classical paradigms. American Journal of Physiology-Heart and Circulatory Physiology, v.316, n.5, p.H958970, 2019.

SANTOS, R. A.; KRIEGER, E. M.; GREENE, L. J. An improved fluorometric assay of rat serum and plasma converting enzyme. Hypertension, v.7, n.2, p.244-252, 1985.

SCHLUTER, K. D. et al. Review on Chamber-Specific differences in right and left heart reactive oxygen species handling. Frontiers in Physiology, v.9, n.1799, 2018.

SCHUTTE, T. D.; TENEYCK, C. J.; SCHUTTE, B. C. Thyroid hormone regulation of the $\mathrm{NADH}$ shuttles in liver and cardiac mitochondria. Journal of Molecular and Cellular Cardiology, v.32, n.1, p.1-10, 2000.

SENGER, N. et al. Angiotensin-(1-7) reduces cardiac effects of thyroid hormone by GSK3ß/NFATc3 signaling pathway. Clinical Science, v. 132, n.11, p.1117-1133, 2018.

SHAH, A. et al. Angiotensin-(1-7) stimulates high atrial pacing-induced ANP secretion via Mas/PI3Kinase/Akt axis and $\mathrm{Na}^{+} / \mathrm{H}^{+}$exchanger. American Journal of Physiology-Heart and Circulatory Physiology, v.298, n.5, p.H1365-H1374, 2010.

SHIMIZU, H. et al. The Calcineurin-FoxO-MURF1 signaling pathway regulates myofibril integrity in cardiomyocytes. Elife, v.6, n.e27955, 2017.

SHINOHARA, R. et al. Lipid peroxidation levels in rat cardiac muscle are affected by age and thyroid status. Journal of Endocrinology, v.164, n.1, p.97-102, 2000. 
SHIOJIMA, I et al. Akt signaling mediates postnatal heart growth in response to insulin and nutritional status. Journal of Biological Chemestry, v.277, n.40, p.37670-37677, 2002.

SIU, C. W. et al. Incidence, clinical characteristics and outcome of congestive heart failure as the initial presentation in patients with primary hyperthyroidism. Heart (British Cardiac Society), v.3, n.4, p.483-487, 2007.

SKURK, C. et al. The FOXO3a transcription fator regulates cardiac myocyte size downstream of Akt signaling. Journal of Biological Chemistry, v.280, n.21, p.20814-20823, 2005.

STITT, T. N. et al. The IGF-1/PI3K/Akt pathway prevents expression of muscle atrophyinduced ubiquitin ligases by inhibiting FOXO transcription factors. Mollecular Cell, v.14, n.3, p.395-403, 2004.

SUN, D. et al. Cardioprotective effects of transhione IIA pretreatment via kinin B2 receptorAkt-GSK-3B dependent pathway in experimental diabetic cardiomyopathy. Cardiovascular Diabetology, v.10, n.4, 2011.

SUNDARESAN, N. R. et al. Sirt3 blocks the cardiac hypertrophic response by augmenting Foxo3a-dependent antioxidant defense mechanisms in mice. Journal of Clinical Investigation, v.119, n.9, p.2758-2771, 2009.

TADEVOSYAN, A. et al. Nuclear-delimited angiotensin receptor-mediated signaling regulates cardiomyocyte gene expression. The Journal of Biological Chemistry, v.285, n.29, p.22338-22349, 2010.

TAKANO, A. P. C. et. al. S100A8/MYD88/NF-kB: a novel pathway involved in cardiomyocyte hypertrophy driven ny thyroid hormone. Journal of Molecular Medicine, v.95, n.6, p.671-682, 2017.

TAKANO, A. P.; DINIZ, G. P.; BARRETO-CHAVES, M. L. AMPK signaling pathways is rapidly activated by $\mathrm{T} 3$ and regulates the cardiomyocyte growth. Molecular Cell Endocrinology, v.376, n.1-2, p.43-50, 2013.

TALEUX, N. et al. High expression of thyroid hormone receptors and mitochondrial glycerol3-phosphate dehydrogenase in the liver is linked to enhanced fatty acid oxidation in Lou/C, a rat strain resistant to obesity. Journal of Biologic Chemistry, v.284, n.7, p.4308-4316, 2008.

TALlANT, E. A.; FERRARIO, C. M.; GALlACHER, P. E. Angiotensin-(1-7) inhibits growth of cardiac myocytes through activation of the mas receptor. American Journal of Physiology. Heart and Circulation Physiology, v.289, n.4, p.H1560-H1566, 2005. 
TAMARGO, M.; TAMARGO, J. Future drug discovery in renin-angiotensin-aldosterone system intervation. Expert Opnion on Drug Discovery, v.12, n.8, p.827-848, 2017.

TAN, W. Q. et al. Foxo3 inhibits cardiomyocyte hypertrophy through transactivating catalase. Journal of Biologic Chemistry, v.283, n.44, p.29730-29739, 2008.

TETZNER, A. et al. G-Protein-couple receptor $\operatorname{MrgD}$ is a receptor for angiotensin-(1-7) involving adenylyl cyclase, cAMP, and phosphokinase A. Hypertension, v.68, n.1, p.185194, 2016.

TEXEIRA, L. B. et al. Ang-(1-7) is an endogenous $\beta$-arrestin-biased agonist of the AT $<$ sub $>1</$ sub $>$ receptor with protective action in cardiac hypertrophy. Scientific Reports, v.7, n.1, 2017.

TOKER, A.; NEWTON, A. C. Akt/protein kinase B is regulated by autophosphorylation at the hypothetical PDK-2. The Journal of Biological Chemistry, v.275, n.12, p.8271-8274, 2000.

TRAN, H. et al. The many forks in FOXO’s road. Science Signaling, v.2003, n.172, 2003.

TREPANEIR, L. A. Medical management of hyperthyroidism. Clinical Techniques in Small Animal Practice, v.21, n.1, p.21-28, 2006.

TRONCOSO, R. et al. Energy-preserving effects of IGF-1 antagonize starvation-induced cardiac autophagy. Cardiovascular Research, v.93, n.2, p.320-329, 2012.

TURPAEV, K. T. Reactive oxygen species and regulation of gene expression. Biochemistry (Moscow), v.67, n.3, p.281-292, 2002.

UCAR, A. et al. The miRNA-212/132 family regulates both cardiac hypertrophy and cardiomyocyte autophagy. Nature Communications, v.3, n.1078, 2012.

VAN DER HORTS, A. et al. FOXO4 is acetylated upon peroxide stress and deacetylated by the longevity protein hSir2(SIRT1). The Journal of Biological Chemistry, v.279, n.28, p.28873-28879, 2004.

VAN KATS, J. P. et al. Angiotensin production by the heart: a quantitative study in pigs with the use of radiolabeled angiotensins infusions. Circulation, v.98, n.1, p.73-81, 1998. 
VANDER HAAR, E. et al. Insulin signaling to mTOR mediated by the Akt/PKB substrate PRAS40. Nature Cell Biology, v.9, n.3, p.316-323, 2007.

VENDITTI, P. et al. Effect of thyroid state on lipid peroxidation, antioxidant defenses and susceptibility to oxidative stress in rat tissues. Journal of Endocrinology, v.155, p.151-157, 1997.

VENDITTI, P.; DI MEO, S. Thyroid hormone-induced oxidative stress. Cellular and Molecular Life Science, v.63, n.4, p.414-434, 2006.

VERANO-BRAGA, T. et al. Time-resolved quantitative phosphoproteomics: New insdights into Angiotensin-(1-7) signaling netwoks in human endothelial cells. Journal of proteome, v.11, n.6, p.3370-3381, 2012.

VILLELA, D. C. et al. Angiotensin type 2 receptor (AT2R) and receptor Mas: a complex liaison. Clinical Science, v.128, n.4, p.227-234, 2015.

VILLELA, D. C.; PASSOS-SILVA, D. G.; SANTOS, R. A. Alamandine: a new member of the angiotensin family. Current Opinion in Nephrology and Hypertension, v.32, n.2, p.130-134, 2014.

WADOSKY, K. M. et al. MURF1 mono-ubiquitinates TR $\alpha$ to inhibits T3-induced cardiac hypertrophy in vivo. Journal of Molecular Endocrinology, v.56, n.3, p.273-290, 2016.

WALTERS, P. E.; GASPARI, T. A.; WIDDOP, R. E. Angiotensin-(1-7) acts as a vasodepressor agent via angiotensin II type 2 receptor in conscious rats. Hypertension, v.45, n.5, p.960-966, 2005.

WANG, K. et al. miR-874 regulates myocardial necrosis by targating caspase- 8 . Cell Death \& Disease, v.4, n.7, 2013.

WANG, W. et al. Identification and characterization of AGTRAP, a human homolog of murine angiotensin II receptor-associated protein (AGTRAP). The International Journal of Biochemistry \& Cell Biology, v.34, n.1, p.93-102, 2002.

WILLIS, M. S. et al. Muscle ring finger 1, but not muscle finger 2, regulates cardiac hypertrophy in vivo. Circulation Research, v.100, n.4, p.456-459, 2007.

XIN, Z. et al. FOXOs in the impaired heart: New therapeutic targets for cardiac diseases. Biochimica et Biophysica Acta, v.1863, n.2, p.486-498, 2017. 
XU, P. et al. Endothelial dysfunction and elevated blood pressure in MAS gene-deleted mice. Hypertension, v.51, n.2, p.574-580,2008.

YAN, W. et al. Chronic blockage of class I PI3-Kinase attenuates Ang II-induced cardiac hypertrophy and autophagic alteration. European Review for Medical and Pharmacological Sciences, v.19, n.5, p.772-783, 2015.

YANG, Y. Y. et al. Protective effect of angiotensin-(1-7) against hyperglycemia-induced injury in $\mathrm{H} 9 \mathrm{C} 2$ cardiomyoblast cells via the PI3K/Akt signaling pathway. International Journal of Molecular Medicine, v.41, n.3, p.1283-1292, 2018.

YAO, H.; HAN, X.; HAN, X. The cardioprotection of the Insulin-Mediated PI3K/Akt/mTOR signaling pathway. American Journal of Cardiovascular Drugs, v.14, n.6, p.433-442, 2014.

YEN, P. M. Physiological and molecular basis of thyroid hormone action. Physiology Reviews, v.81, p.1097-1142, 2001.

YOUNG, D. et al. Isolation and Characterization of a new cellular oncogene encoding a protein with multiple potential transmembrane domains. Cell, v.45, n.5, p.711-719, 1986.

ZENG, Y. et al. Transcriptional effects of E3 ligase atrogin-1/MAFbx on apoptosis, hypertrophy and inflammation in neonatal rat cardiomyocytes. PLOS ONE, v.8, n.1, 2013.

ZHAI, P. et al. Differential roles of GSK-3 $\beta$ during myocardial ischemia and ischemia/reperfusion. Circulation Research, v.109, n.5, p.502-511, 2011.

ZHANG, C. et al. Metformin attenuates ventricular hypertrophy by activating the AMPactivated protein kinase-endothelial nitric oxide synthase pathway in rats. Clinical and Experimental Pharmacology and Physiology, v.38, n.1, p.55-62, 2011a.

ZHANG, F. et al. Angiotensin-(1-7) abrogates angiotensin II-induced proliferation, migration and inflammation in VSMCs through inactivation of ROS-mediated PI3K/Akt and MAPK/ERK signaling pathways. Scientific Reports, v.6, 2016.

ZHANG, T. et al. Inhinition of Mas G-protein signaling improves coronary blood flow, reduces myocardial infarct size, and provides long-term cardioprotection. American Jorunal of Physiological-Heart Circulatory Physiology, v.302, n.1, p.H299-H311, 2011 b.

ZHAO, P. et al. Angiotensin1-7 protects cardiomyocytes from hypoxia/reoxygenationinduced oxidative stress by preventing ROS-associated mitochondrial dysfunction and activating the Akt signaling pathway. Acta Histochemica, v.117, n.8, p.803-810, 2015. 
ZHOU, J. P. et al. Angiotensin-(1-7) decreases the expression of collagen I via TGFB1/Smad2/3 and subsequently inhibits fibroblast-myofibroblast transition. Clinical Science, v.130, p.1983-1991, 2016.

ZONCU, R. et al. mTORC1 senses lysosomal amino acids through an inside-out mechanism that requires the vacuolar H-ATPase. Science, v.334, v.6056, p.678-683, 2011. 